Article

\title{
The Environmental Assessment on Chinese Logistics Enterprises Based on Non-Radial DEA
}

\author{
Jie Liu ${ }^{1, *}$, Chunhui Yuan ${ }^{1}$ and Xiaolong $\mathrm{Li}^{2, *}$ \\ 1 School of Economics and Management, Beijing University of Posts and Telecommunications, \\ Beijing 100876, China; yuanchunhuibupt@163.com \\ 2 School of Modern Post, Beijing University of Posts and Telecommunications, Beijing 100876, China \\ * Correspondence: liujie4869@126.com (J.L.); tell714@gmail.com (X.L.); \\ Tel.: +86-188-1097-3901 (J.L.); +86-138-1131-8321 (X.L.)
}

Received: 26 November 2019; Accepted: 11 December 2019; Published: 13 December 2019

check for updates

\begin{abstract}
Under the new situation of economic development in China, the logistics industry is facing unbalanced development regarding economic and environmental performance. From the enterprise level, this study investigated the sustainability of Chinese logistics based on the environmental assessment data envelopment analysis (DEA) model, and measured the unified efficiency of a logistics company under two different production arrangement strategies. The empirical measurement provides several findings. First, logistics enterprises give higher priority to operational benefits than environmental performance. Second, under the operational priority of production arrangement, small and medium-sized enterprises' (SMEs) unified efficiency is better than a large enterprise, and private enterprises' unified efficiency is better than state-owned enterprises. Moreover, the empirical study has further proved that the sustainability development of Chinese logistics is still at the primary stage; when facing trade-offs in the sustainability context, logistics companies still prioritize operational performance first. Therefore, transforming corporate strategy into an environmental sustainable priority and realizing logistics sustainability still has a long way to go, which is the backbone of realizing balanced development of both the economy and environment.
\end{abstract}

Keywords: sustainability; green logistics; Chinese logistics; DEA

\section{Introduction}

As one of the biggest sources of global greenhouse gas (GHG) emissions, transportation comprises $23 \%$ of global energy-related emissions in 2018 , and $92 \%$ of its energy demand depends on oil [1]. The contribution of freight transportation to total transport emissions is $39 \%$, and is expected to be at least equivalent to passenger transport by 2050 [2]. According to Intergovernmental Panel on Climate Change (IPCC), driven by the rapidly growing economies in Asia, Africa, and Latin America, freight transport demand is predicted to increase three-fold by 2050. Environmental sustainability in freight transportation has drawn immense concern in both research and practice areas.

Freight transportation plays a key role in supply chain operation, and the environmental sustainability concern has sparked tremendous interest towards optimal supply chain networks that balance both economic and environmental influences. Under the framework of sustainable supply chain management (SSCM), logistics is a relatively small topic, with most researches focused on broader areas of the supply chain or focal supply chain members, which are usually manufactures [3]. The existing studies on environmentally sustainable logistics appear to focus on models for reducing emissions or the relationships between logistics activities and environmental impacts [4]. From the enterprise perspective, despite pressures or governmental regulations to reduce GHG emissions, companies may still plan to continue their original environmental strategies [5]. While in the long 
run, to survive under this carbon-constrained business environment, companies have to adjust their business strategies to deal with various environmental constrains [6]. Additionally, transportation is one of the few GHG emissions sources that enterprises can efficiently influence [5]. Therefore, at the enterprise level, it is important, even fundamental, to figure out how logistics companies arrange their production resources to cope with environmental pressures, and how efficient their production strategy is under the environmental sustainability concern.

In 2018, the total expenses on Chinese logistics activities were up to 13.3 trillion yuan, which makes China the biggest freight transportation market around the world [7]. Driven by economic growth and the increasing consumption demand, logistics has become the backbone of the Chinese economy. Since the construction of ecological civilization became one of the key objectives of China's Thirteenth Five-Year Plan (2016-2020), the "Construction of Ecological Civilization" in the transportation sector has been stressed by the Ministry of Ecology and Environment and the Ministry of Transport of China. Environmental regulation on freight transportation and logistics from the government places high pressure on logistics companies to enhance their environmental performance.

Despite the tremendous concerns from macro regulations toward environmental performance in the logistics sector, the sustainable development of Chinese logistics is still in its infancy [8]. When first confronted with environmental regulations, enterprises resist change and give more preferences to commercial concerns in the trade-off between environmental protection and economic benefits [9]. It is essential to evaluate and analyze the environmental efficiency under the trade-off between environment and economic benefits during the operational process of logistics enterprises. Therefore, the main objective of this paper was to measure the environmental efficiency of Chinese logistics enterprises under different sustainable strategies, in order to fundamentally figure out the development stage of environmental sustainability and give implications to enterprises' business strategy arrangement and government environmental regulations.

Data envelopment analysis (DEA) has recently become one of the important tools for environmental assessment in the sustainability area. The DEA methodology was first proposed by professor A. Charnes and professor W.W. Cooper in 1978 [10]. Since then, DEA has become a major approach for performance assessment in various organizations. As an approximation approach, it could provide an empirical guideline for enterprises and policy makers. After the concept of undesirable output was proposed by Färe [11], the use of DEA for environmental assessment has drawn attention from researchers in the sustainability development area. Nowadays, environment sustainability has become the most popular application area of DEA [12].

Previous literature that uses DEA for environmental assessment operates on multiple levels. At the country level, Camarero, Castillo [13] used DEA to determine the eco-efficiency of a group of 22 The Organisation for Economic Co-operation and Development (OECD) countries, and a similar research was also conducted in European Union countries [14]. Cui and Li [15] evaluated transportation carbon efficiencies from 15 countries. Research at the country level is more focused on a comparison between macro economies [16], which could provide policy implications for global and national sustainability.

As to the regional level, China's environmental efficiency has been explored by several studies using different production factors [17-19]. Sueyoshi and Yuan [19] explored the regional sustainability development of China by incorporating particulate matter (PM) 2.5 and PM10 as undesirable outputs. Another research by Zhou and Chen [17] explored the environmental efficiency of 30 provinces in China based on a DEA environmental assessment radial model. The regional environmental efficiency displays the direction of government policy for environmental protection and economic development, and could give implications for industries' sustainable development.

At the industry level, the majority of studies are based on the energy sector, such as petroleum firms, solar thermal power stations, petroleum coal-fired power plants, and fossil fuel power generation [20-24]. Additionally, Li and Zhang [25] also investigated provincial differences in fossil fuel power plants in China. The energy industry is one of the most concerned sectors under sustainability circumstances, and efficiency measurement can give instructions for the arrangement of energy production in a certain 
country. In the manufacture industry, Sueyoshi and Goto [26] applied DEA environmental assessment to Japanese industrial enterprises to explore the unified efficiency on differently prioritized resource arrangements (operational and environmental). Another research of Sueyoshi and Goto [27] explored the sustainability of Japanese enterprises, which included manufacturing firms and non-manufacturing firms, and found that manufacturing firms outperform non-manufacturing ones in operations. According to previous literatures, except for researches focused on energy production, studies that investigated environmental efficiency at the enterprise level are usually from multiple industry sectors.

When it comes to logistics and freight transportation, few studies have adopted the DEA method to explore environmental efficiency in the transport sector. Yang and Taudes [28] used DEA to measure the efficiency of 20 freight villages in Europe but did not consider any environmental outputs. Haralambides and Gujar [29] applied DEA to evaluate dry port efficiency in India while taking into account the undesirable environmental output. Another study focused on public transportation in Iran, and developed a DEA-based target-setting methods to set targets for 24 bus companies under green supply chain management requirements [30]. In China, Li and Meng [31] investigated the sustainability performance of the transportation industry under environmental regulations by using provincial data in China. Different with those traditional manufacture enterprises, such as the automobile industry or paper-making industry, the production network of logistics enterprises has a higher degree of regional crossover, which may bias the regional level of sustainability efficiency. Yet, there has not been any literature that explores the environmental efficiency of freight transportation from the enterprise perspective.

According to those previous studies, though DEA assessment has been employed in port and public transport companies in other countries, environmental efficiency in the logistics and freight transport sector should be investigated more comprehensively. Studies on environmental efficiency assessment using the DEA method in Chinese freight transport companies is still blank. Therefore, the aim of this study was to fill the aforementioned gap in the Chinese logistics sector under the environmental sustainability consideration. This paper intended to investigate the environmental efficiency of logistics enterprises in China by using the DEA model under different operational priorities.

The rest of this paper is organized as follows. Section 2 describes the two disposability concepts and the methodology of DEA environmental assessment by a non-radial model. In Section 3, the environmental assessment of Chinese logistics enterprises is illustrated, and the unified efficiencies under natural and managerial disposability are calculated. Subsequently, statistical tests are employed to explore the differences between groups classified by enterprise size and ownership. Section 4 presents the conclusions and implications of this study.

\section{The Methodology of Non-Radial DEA}

This study applied non-radial DEA models for environmental assessment, as proposed by Sueyoshi and Goto [24]. The DEA model for environmental assessment needs to fully utilize all kinds of production factors (the inputs, desirable outputs, and undesirable outputs), and this requirement needs all dual variables in the model to be positive or zero. In this circumstance, the non-radial model could be the one that satisfies the requirements. Moreover, given the output factors, such as the net income of a certain enterprise could be negative, the property of the translation invariance of thee non-radial model makes it possible to evaluate the efficiency of DMUs (decision-making units) whose inputs or outputs contain zero/or negative values [32]. Therefore, the non-radial DEA model was adopted to measure the efficiency of logistics enterprises under environmental regulation in China.

\subsection{Nomenclatures Used in the DEA Model}

The nomenclatures used in the non-radial DEA models are summarized as follows:

Notations of production factors that are observed from the data set:

$x_{i j}: i$-th input of the $j$-th DMU $(i=1, \ldots$, m and $j=1, \ldots, \mathrm{n})$;

$g_{r j}: r$-th desirable output of the $j$-th DMU $(r=1, \ldots$, s and $j=1, \ldots, \mathrm{n})$; and 
$b_{f j}: f$-th undesirable output of the $j$-th $\operatorname{DMU}(f=1, \ldots$, h and $j=1, \ldots, \mathrm{n})$.

Notations of other unknown variables that need to be measured:

$d_{i}^{x}$ : A slack variable of the $i$-th input $(i=1, \ldots, \mathrm{m})$;

$d_{r}^{g}$ : A slack variable of the $r$-th desirable output $(r=1, \ldots, \mathrm{s})$;

$d_{f}^{b}$ : A slack variable of the $f$-th undesirable output $(f=1, \ldots, h)$;

$R_{i}^{x}$ : The range for the $i$-th input $(i=1, \ldots, \mathrm{m})$ which makes it for full utilization;

$R_{r}^{g}$ : The range for the $r$-th desirable output $(r=1, \ldots, \mathrm{s})$ which makes it for full utilization;

$R_{f}^{b}$ : The range for the $f$-th undesirable output $(f=1, \ldots, \mathrm{h})$ which makes it for full utilization; and

$\lambda_{j}$ : An unknown variable of the $j$-th intensity variable $(j=1, \ldots, n)$ to connect production factors.

\subsection{Disposability Concepts}

In this non-radial DEA applied to environmental assessment, two important disposability concepts are the basis of the environmental assessment DEA framework: The "natural disposability" and "managerial disposability", where the concept of disposability implies the elimination of inefficiency [33].

Natural disposability: Natural disposability indicates that a decision-making unit (DMU) decreases the undesirable outputs by reducing the inputs. Considering the decreasing inputs, the DMU is dedicated to increasing the desirable outputs as much as possible. Natural disposability implies that the operational performance of DMU is the first criterion, and companies reduce their inputs in order to reduce the undesirable outputs. In another words, enterprises under natural disposability would use a negative way, such as reducing the operation scale, to deal with environmental regulation while in the meantime, they try to maximize their desirable outputs.

Managerial disposability: Managerial disposability indicates that a DMU decreases the undesirable outputs by increasing the inputs. On the basis of the increasing inputs, the DMU is dedicated to increasing the desirable outputs as much as possible. Managerial disposability implies that the environmental performance of the DMU is the first criterion, and companies increase their inputs in order to reduce the undesirable outputs. Enterprises under managerial disposability take environmental regulation as an opportunity to enhance their unified efficiency by using environmental technologies or new management. This is a positive way to deal with environmental regulation, and it gives the same propriety to both economic and environmental performance.

The axiomatic expressions of the disposability are as follows:

It considers $\mathrm{X} \in R_{+}^{m}$ as the vector for inputs with m components, $G \in R_{+}^{s}$ as the vector for desirable outputs with s components, and $B \in R_{+}^{h}$ as the vector for undesirable outputs with $\mathrm{h}$ components. The $j$ stands for the $j$-th DMU. Those three kinds of vectors are production factors. The unified production and environmental emissions possibility set to express natural and managerial disposability are as follows:

$$
\begin{aligned}
& P_{v}^{N}(X)=\left\{(G, B): G \leq \sum_{j=1}^{n} G_{j} \lambda_{j}, B \geq \sum_{j=1}^{n} B_{j} \lambda_{j}, X \geq \sum_{j=1}^{n} X_{j} \lambda_{j}, \sum_{j=1}^{n} \lambda_{j}=1 \& \lambda_{j} \geq 0(j=1, \ldots, n)\right\}, \\
& P_{v}^{M}(X)=\left\{(G, B): G \leq \sum_{j=1}^{n} G_{j} \lambda_{j}, B \geq \sum_{j=1}^{n} B_{j} \lambda_{j}, X \leq \sum_{j=1}^{n} X_{j} \lambda_{j}, \sum_{j=1}^{n} \lambda_{j}=1 \& \lambda_{j} \geq 0(j=1, \ldots, n)\right\},
\end{aligned}
$$

where $P_{v}^{N}(X)$ stands for a possibility set under natural disposability, and $P_{v}^{M}(X)$ stands for a possibility set under managerial disposability. $v$ stands for variable RTS (returns to scale) or DTS (damages to scale) since the constraint $\left(\sum_{j=1}^{n} \lambda_{j}=1\right)$ is in those two axiomatic expressions. In the axiomatic expressions, the two concepts both have $G \leq \sum_{j=1}^{n} G_{j} \lambda_{j}, B \geq \sum_{j=1}^{n} B_{j} \lambda_{j}$, which indicates that an efficiency frontier for all desirable outputs should be located above or on observations, and all undesirable outputs should be located below or on observations. Meanwhile, the difference between the two disposability 
concepts is that $P_{v}^{N}(X)$ has $X \geq \sum_{j=1}^{n} X_{j} \lambda_{j}$, implying that a company can attain the efficiency frontier by reducing a directional vector of inputs while $P_{v}^{M}(X)$ has $X \leq \sum_{j=1}^{n} X_{j} \lambda_{j}$, implying that a company can attain the efficiency frontier by increasing a directional vector of inputs.

Compared to traditional DEA, which usually assumes a capacity limit on the production system, the DEA environmental assessment is dedicated to discussing how to balance economic benefit and environmental protection. In other words, the production cost is determined according to the marginal cost (variable RTS and DTS), rather than the total cost in traditional DEA evaluation [18,33]. The natural disposability and managerial disposability are linked to the operational difficulty and eco-technology innovation on undesirable outputs, such as $\mathrm{CO}_{2}$ emissions. Therefore, the measurement of efficiency is in the context of sustainability, which can provide a more comprehensively environmental assessment result.

\subsection{Non-Radial Approach for Unified Efficiency Measures}

The unified efficiency of DMU in this non-radial model separates the slack variables of the $i$-th input into positive and negative parts $\left(d_{i}^{x+}\right.$ and $\left.d_{i}^{x-}\right)$ to illustrate the two kinds of disposability. The unified efficiency $\left(U E_{v}^{N R}\right)$ for the $k$-th DMU can be reformulated under natural and managerial disposability. The NR stands for the non-radial measure, and $v$ refers to variable RTS and DTS. The magnitude of $U E_{v}^{N R}$ is measured by the following model:

$$
\begin{array}{cc}
\text { Maximize } & \sum_{i=1}^{m} R_{i}^{x}\left(d_{i}^{x+}+d_{i}^{x-}\right)+\sum_{r=1}^{s} R_{r}^{g} d_{r}^{g}+\sum_{f=1}^{h} R_{f}^{b} d_{f}^{b} \\
\text { s.t. } \quad & \sum_{j=1}^{n} x_{i j} \lambda_{j}-d_{i}^{x+}+d_{i}^{x-}=x_{i k}(i=1, \ldots, m), \\
& \sum_{j=1}^{n} g_{r j} \lambda_{j}-d_{r}^{g}=g_{r k}(r=1, \ldots, s), \\
& \sum_{j=1}^{n} b_{f j} \lambda_{j}+d_{f}^{b}=b_{f k}(f=1, \ldots, h), \\
& \sum_{j=1}^{n} \lambda_{j}=1, \\
\lambda \geq 0, d_{i}^{x+} \geq 0 \text { for all } i, d_{i}^{x-} \geq 0 \text { for all } i, \\
d_{r}^{g} \geq 0 \text { for all } r, d_{f}^{b} \geq 0 \text { for all } f .
\end{array}
$$

In the proposed Equation (3), the production factors are adjusted by the data ranges. This study uses the following three types of data ranges according to the upper and lower bounds on each production factor. The data range adjustment can be used to control the magnitude of the unified efficiency measure between full efficiency and inefficiency [33]:

$$
\begin{aligned}
& R_{i}^{x}=(m+s+h)^{-1}\left(\max \left\{x_{i j} \mid j=1, \ldots, n\right\}-\min \left\{x_{i j} \mid j=1, \ldots, n\right\}\right)^{-1}, \\
& R_{r}^{g}=(m+s+h)^{-1}\left(\max \left\{g_{r j} \mid j=1, \ldots, n\right\}-\min \left\{g_{r j} \mid j=1, \ldots, n\right\}\right)^{-1}, \\
& R_{f}^{b}=(m+s+h)^{-1}\left(\max \left\{b_{f j} \mid j=1, \ldots, n\right\}-\min \left\{b_{f j} \mid j=1, \ldots, n\right\}\right)^{-1} .
\end{aligned}
$$

Based on the optimal solution from Equation (3), the $U E_{v}^{N R}$ score on optimality is as follows:

$$
U E_{v}^{N R}=1-\left(\sum_{i=1}^{m} R_{i}^{x}\left(d_{i}^{x+*}+d_{i}^{x-*}\right)+\sum_{r=1}^{s} R_{r}^{g} d_{r}^{d^{* *}}+\sum_{f=1}^{h} R_{f}^{b} d_{f}^{b *}\right) .
$$

In this non-radial approach, the vector $\lambda=\left(\lambda_{1}, \ldots, \lambda_{n}\right)^{T r}$ in Equation (3), as the intensity or the structural vector, is used for connecting the production factors by a convex combination. The production and pollution possibility set for Equation (3) is structured under variable RTS and DTS. The slack variables represent the level of inefficiency, and the level of inefficiency is determined on the optimality of Equation (3) by the total amount of slacks. Therefore, Equation (5) expresses the level of unified efficiency. 


\subsection{Unified Efficiency under Natural Disposability}

The non-radial model under natural disposability $(\mathrm{N})$ is used to measure the unified efficiency of the $k$-th DMU, and is formulated by the following model:

$$
\begin{gathered}
\text { Maximize } \sum_{i=1}^{m} R_{i}^{x} d_{i}^{x-}+\sum_{r=1}^{s} R_{r}^{g} d_{r}^{g}+\sum_{f=1}^{h} R_{f}^{b} d_{f}^{b} \\
\text { s.t. } \sum_{j=1}^{n} x_{i j} \lambda_{j}+d_{i}^{x-}=x_{i k}(i=1, \ldots, m), \\
\sum_{j=1}^{n} g_{r j} \lambda_{j}-d_{r}^{g}=g_{r k}(r=1, \ldots, s), \\
\sum_{j=1}^{n} b_{f j} \lambda_{j}+d_{f}^{b}=b_{f k}(f=1, \ldots, h), \\
\sum_{j=1}^{n} \lambda_{j}=1, \\
\lambda \geq 0, d_{i}^{x-} \geq 0 \text { for all } i, d_{r}^{g} \geq 0 \text { for all } r, d_{f}^{b} \geq 0 \text { for all } f .
\end{gathered}
$$

In order to attain the strategy under natural disposability, Equation (6) only considers the slack variable, $d_{i}^{x-}$, related to the inputs. The unified efficiency under natural disposability (UEN) is measured by Equation (7), where all slack variables are obtained from the optimality of Equation (6). The equation within the parentheses expresses the level of inefficiency under natural disposability, and the unified efficiency formulated in Equation (7) is obtained by subtracting the score of the inefficiency from the unity:

$$
U E N_{v}^{N R}=1-\left(\sum_{i=1}^{m} R_{i}^{x} d_{i}^{x-*}+\sum_{r=1}^{s} R_{r}^{g} d_{r}^{g *}+\sum_{f=1}^{h} R_{f}^{b} d_{f}^{b *}\right) .
$$

\subsection{Unified Efficiency under Managerial Disposability}

Compared with the UEN, the unified efficiency under managerial disposability (M) puts the environmental performance of DMU as the first priority. The non-radial model under managerial disposability to measure the unified efficiency of the $k$-th DMU is formulated by the following model:

$$
\begin{gathered}
\text { Maximize } \sum_{i=1}^{m} R_{i}^{x} d_{i}^{x+}+\sum_{r=1}^{s} R_{r}^{g} d_{r}^{g}+\sum_{f=1}^{h} R_{f}^{b} d_{f}^{b} \\
\text { s.t. } \quad \sum_{j=1}^{n} x_{i j} \lambda_{j}-d_{i}^{x+}=x_{i k}(i=1, \ldots, m), \\
\sum_{j=1}^{n} g_{r j} \lambda_{j}-d_{r}^{g}=g_{r k}(r=1, \ldots, s), \\
\sum_{j=1}^{n} b_{f j} \lambda_{j}+d_{f}^{b}=b_{f k}(f=1, \ldots, h), \\
\sum_{j=1}^{n} \lambda_{j}=1, \\
\lambda \geq 0, d_{i}^{x+} \geq 0 \text { for all } i, d_{r}^{g} \geq 0 \text { for all } r, d_{f}^{b} \geq 0 \text { for all } f .
\end{gathered}
$$

In order to attain the strategy under managerial disposability, Equation (8) only considers the slack variable, $d_{i}^{x+}$, related to the inputs. The unified efficiency under managerial disposability (UEM) is measured by Equation (9), where all slack variables are obtained from the optimality of Equation (8). The equation within the parentheses expresses the level of inefficiency under managerial disposability, and the unified efficiency formulated in Equation (9) is obtained by subtracting the score of inefficiency from unity:

$$
U E M_{v}^{N R}=1-\left(\sum_{i=1}^{m} R_{i}^{x} d_{i}^{x+*}+\sum_{r=1}^{s} R_{r}^{g} d_{r}^{g^{*}}+\sum_{f=1}^{h} R_{f}^{b} d_{f}^{b *}\right) .
$$

\section{The Environmental Assessment of Chinese Logistics Enterprises}

\subsection{Variables and Data}

This study chose four input variables, two desirable output variables, and one undesirable output variables. The four inputs were as follows: (a) Total assets, it refers to the total amount of assets owned by each company, and it is the sum of all current and noncurrent assets; (b) total operating expenses, operating expenses are the total expenses in a company's day-to-day regular operations, such as sale 
and management expenses; (c) employee, this is the total number of each company's employees; and (d) energy consumption, this is the total amount of fossil fuel and electricity consumption in each company's operation. The two desirable outputs were revenue and net income. Revenue refers to the total income generated from the sale of goods or services before any expenses are deducted. Net income is the total revenue minus all expenses in an accounting period. The undesirable output was $\mathrm{CO}_{2}$ emissions, and the $\mathrm{CO}_{2}$ emissions is from scope 1 and scope 2. According to the GHG Protocol Corporate Accounting and Reporting Standard [34], scope 1 emissions are direct emissions from a company's controlled sources; scope 2 emissions are indirect emissions, such as electricity purchased and used by a company; and scope 3 emissions are all other indirect emissions, which were not included in our data collection.

One of the major challenges in environmental assessment at the enterprise level is environmental data collection and standardization, especially in the freight transportation area. According to the review of Ellram and Murfield [5], there are very few comprehensive data sets on transportation emissions (such as by source, time horizon, or freight and passenger). Using empirical data to establish a baseline for environmental transportation performance is critical to understand the impact of freight transportation on sustainability. Considering this, the study collected environmental secondary data from enterprises' corporate sustainability report (CSR) disclosures. All samples were collected from China's listed freight transportation companies. The emissions and energy consumption data were collected from the database of Hong Kong Exchanges and Clearing Limited (SEHK), which contains environmental sustainable disclosures of listed companies. The other inputs and outputs were collected from the Wind Economic Database, which is the most comprehensive database on China's economy and industries.

Due to the data availability, 32 out of 58 enterprises in the industrial transportation sector were selected. The total income of the collected enterprises accounts for around $80 \%$ of the whole freight transportation sector in SEHK. Considering the environmental information of a listed company changed to mandatory disclosure in 2016, both financial and environmental data were collected from the last three years (2016-2018). Descriptive statistics of the data are shown in Table 1.

Table 1. Descriptive statistical data.

\begin{tabular}{ccccc}
\hline Variables & Unit & Mean & Min. & Max. \\
\hline Total assets & million USD & 5070.51 & 11.50 & $33,241.61$ \\
Operating expense & million USD & 1809.88 & 6.47 & $17,142.98$ \\
Employee & person & 6843.00 & 41.00 & 40,300 \\
Energy consumption & tce & 443,000 & 42.52 & $7,630,000$ \\
Revenue & million USD & 1933.36 & 2.08 & $17,549.22$ \\
Net income & million USD & 152.39 & -33.05 & 924.94 \\
$\mathrm{CO}_{2}$ emissions & tons & $1,030,000$ & 185.40 & $16,000,000$ \\
\hline
\end{tabular}

\subsection{Results and Discussions}

\subsubsection{Unified Efficiency of Enterprises}

In the selected data set, the occurrence of negative values is observed in net income since enterprises may encounter losses in a certain financial year. Considering the property of translation invariance of the non-radial model, the two desirable output variables were shifted towards the positive direction to eliminate the negative values while the efficiency measure was not influenced [35].

Given the service types provided by the collected logistics companies, the 32 companies were divided into 3 different service modes: Logistics service provider (LSP), port, and ocean carrier. The statistical character of the input and output factors indicates different service features of the three modes. Among those three enterprise groups, the average energy consumption of ocean carriers is the highest while the average employee of LSP is the highest. The UEN was calculated by Equation (7), and the UEM was calculated by Equation (9). Tables A1-A3 in the Appendix A present the unified 
efficiency of each company from the LSP, port, and ocean carrier separately. Each table presents the UEN and UEM scores of the listed company from 2016 to 2018.

The companies in the LSP group mainly supply integrated logistics services, such as transportation, warehouse, supply chain solutions, express delivery, and any other customized services in supply chain operation, and the process of operation could contain multiple transportation modes. The UEN and UEM of each company and average scores all indicate high levels of efficiency under both natural and managerial disposability while the UEN is higher than the UEM score on each LSP enterprise.

The companies belonging to the port group mainly provide comprehensive port services, such as port management and operation, dock service, container handling, and any other related business. The average score of UEN is 0.979 and the average score of UEM is 0.729 .

The companies in the ocean carrier group mainly focus on shipping transportation, especially on international shipping operation, maritime service, and ship chartering, and most of the enterprises have their own cargo ship. Similarly, the UEN is higher than the UEM score on each ocean carrier enterprise. The average score of UEN is 0.989 and the average score of UEM is 0.616.

Comparing the UEN of all enterprises, the UENs range between 0.9 and 1 . The average efficiency under natural disposability of LSP is 0.993 , higher than the port and ocean carrier, while the average value of UEN in ocean carriers is the lowest. The scores of UEM are between 0.3 and 1 . The UEM of each enterprise is lower than its UEN. The average UEM in LSPs is 0.729 , the average UEM of the port is 0.709 , and the average UEM of the ocean carrier is 0.678. Apparently, the LSPs have a higher unified efficiency under both natural and managerial disposability.

Figure 1 displays the average UEN scores of each logistics enterprise. The color indicates the different service modes, and the company name is shown as the company's stock symbol (the links of the stock symbol and company name are displayed in Table A4 in the Appendix A). The performance of LSP under natural disposability is better than the other two service types: Only 2 out of 10 LSPs do not have the unit score, which means the production arrangement under natural disposability achieved full efficiency. Meanwhile, the majority of the efficiency scores in the port and ocean carrier groups does not reach the efficiency frontier, and the minimum UEN is in the port company.

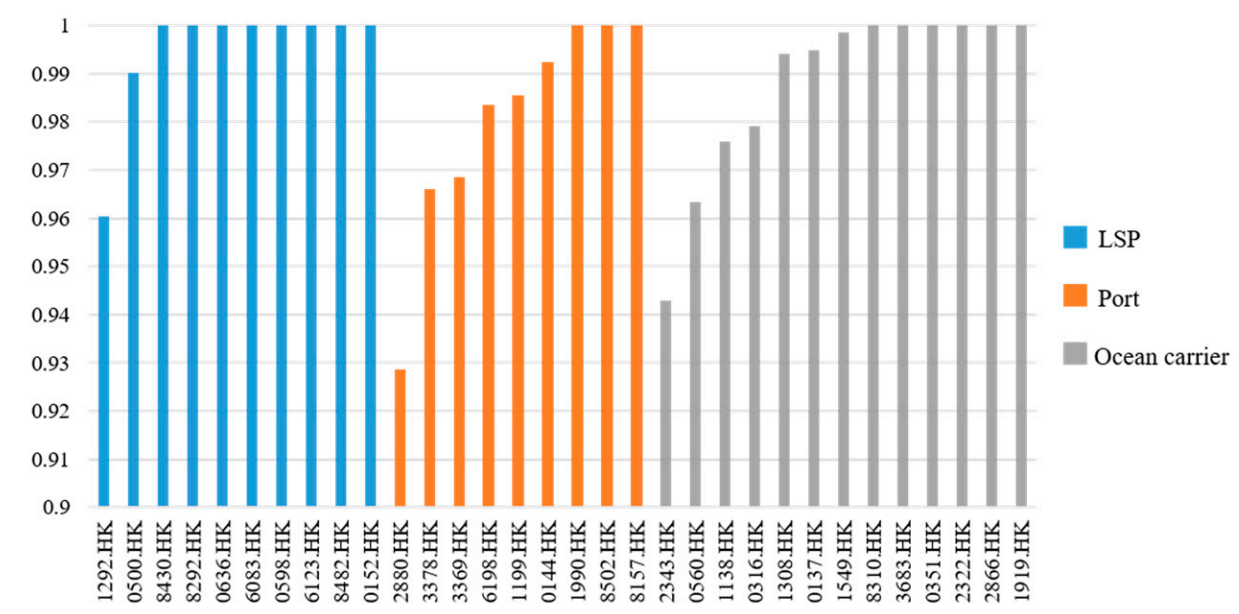

Figure 1. The average UEN of logistics enterprises.

Figure 2 shows the average UEM scores of each logistics enterprise, with the meaning of the color and company name the same as in Figure 1. It is obvious that the efficiency under managerial disposability varies more significantly. The unified efficiency of LSPs is still the highest compared to port and ocean carriers. Four out of seven DMUs with UEM values higher than 0.9 are LSP companies. While the efficiency of ocean carriers contains more low scores, most DMUs with UEM values under 0.5 are ocean carriers. The lower efficiency under managerial disposability of ocean carriers could be due to the high energy consumption in the maritime compared with other fright transportation modes [7]. 


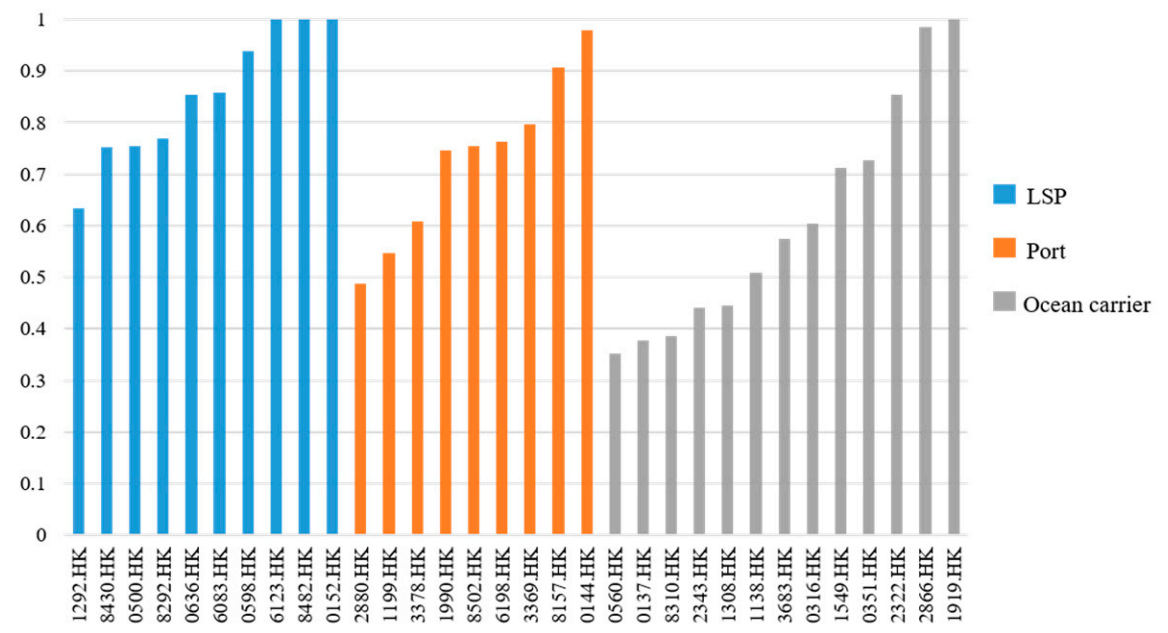

Figure 2. The average UEM of logistics enterprises.

Based on the aforementioned results from each company, the high average UEN and the relatively lower average UEM of logistics enterprises indicate that the business strategies of Chinese logistics companies still put economic benefits at a high priority when facing environmentally sustainable pressure. According to Jeswani and Wehrmeyer [9], when first confronted with environmental constraints, companies may resist change and use negative strategies. Therefore, these results are consistent with the primary development stage of sustainability in China's logistics industry. Additionally, under the new situation of economic transition in China, the key point of the industry structure has shifted to internet-based industry, such as e-commerce. Additionally, this transition would promote freight transportation and logistics to move into a bigger market, which also means increased $\mathrm{CO}_{2}$ emissions and more severe environmental constraints [36]. Therefore, under the sustainability business circumstance, Chinese logistics companies should consider not only the operational performance but also more proactive actions towards emissions reduction and environmental protection, such as using clean technology and improvement of management efficiency.

\subsubsection{Unified Efficiency Grouped by Enterprise Size and Ownership}

To further explore the environmental performance under the two disposability scenarios, this study classified the logistics enterprises into different groups by enterprise size and ownership separately.

1. Grouped by enterprise size. The data set was divided into two groups by enterprise size: Small and medium enterprises (SMEs) and large enterprises. The classification of enterprise size was adopted from the standard of National Bureau of Statistics in China [37]. The standard defines large enterprises in the transportation sector as employing more than 1000 people with a revenue of more than 300 million RMB while enterprises with less than 1000 employees and less than 300 million RMB revenue are defined as SMEs.

2. Grouped by ownership. The logistics companies were classified into two categories according to their ownership: (a) State-owned enterprises, state-owned enterprises are under the supervision of the national or local government, and the government has significant control through full, majority, or significant minority ownership; and (b) private enterprises, which refer to companies that operate under independent firms or individuals, and are free from government intervention.

Figure 3 is the treemap of the 32 enterprises classified by ownership and enterprise size. Obviously, all state-owned enterprises belong to the large enterprise group while the private enterprises have different company sizes, from large corporations to micro enterprises employing a handful of people. The classifications of each company by sample size and ownership are displayed in Table A4 in the Appendix A. 


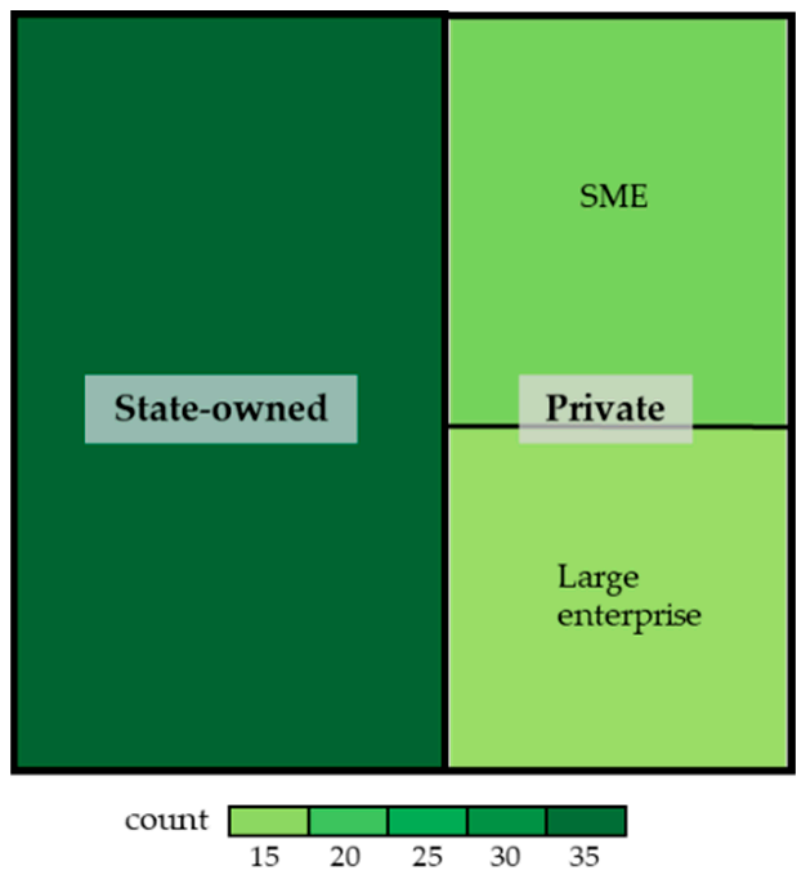

Figure 3. The amount of enterprises classified by ownership and enterprise size.

Table 2 presents the unified efficiency of groups divided by enterprise ownership and size. According to the efficiency of companies grouped by enterprise size, the UEN average of SMEs is 1 , and the UEN average of large enterprises is 0.982 , lower than SMEs. Similarly, the UEM average of SMEs (0.780) is higher than the large enterprises (0.685). Meanwhile, the standard deviations of SMEs are smaller than large enterprises from both UEN and UEM. Apparently, the unified efficiency of SMEs shows a better performance under both natural and managerial disposability.

Table 2. Unified efficiency grouped by enterprise size and ownership.

\begin{tabular}{cccc}
\hline Groups & Statistics & UEN & UEM \\
\hline Enterprise Size & & & \\
\hline & Average & 1.000 & 0.780 \\
SME & Max. & 1.000 & 1.000 \\
& Min. & 0.999 & 0.574 \\
& S.D. & 0.001 & 0.108 \\
\hline \multirow{2}{*}{ Large enterprise } & Average & 0.982 & 0.685 \\
& Max. & 1.000 & 1.000 \\
& Min. & 0.928 & 0.300 \\
Ownership & S.D. & 0.023 & 0.228 \\
\hline \multirow{3}{*}{ State-owned } & & & \\
& Average & 0.982 & 0.717 \\
& Max. & 1.000 & 1.000 \\
& Min. & 0.928 & 0.300 \\
& S.D. & 0.025 & 0.235 \\
\hline \multirow{2}{*}{ Private } & Average & 0.991 & 0.701 \\
& Max. & 1.000 & 1.000 \\
& Min. & 0.937 & 0.376 \\
& S.D. & 0.018 & 0.185 \\
\hline
\end{tabular}


Given this comparison of enterprise size, the differences between the two groups are intriguing. The differences between large enterprises and SMEs indicate that the production factors are better arranged in SMEs from operational priorities. The higher score of UEN in SMEs is in line with the survey of Lin and Ho [38] based on Chinese logistics companies. Due to the limited resources, SMEs tend to give priority to the improvement of core business activities rather than improving environmental performance. According to Kudla and Klaas-Wissing [39], the size of logistics companies may have an impact on their attitudes towards green initiatives. Considering that environmental sustainability in the Chinese logistics sector is still at the primary stage, SMEs usually provide less service categories with a smaller scale of transportation instruments than large enterprises, which could make the operational adjustment more agile when facing environmental regulations. Given the greater organizational structure and higher management cost in large logistics enterprises, it may take a more complex arrangement and longer time to adjust the sustainable business context. Moreover, in order to achieve better competition advantages, SMEs also face higher pressure from downstream supply chain partners in environmental sustainability. Therefore, the UEM in SMEs could be higher than large logistics companies at this early stage of environmental sustainability in the logistics industry.

As to the comparison of efficiency from state-owned and private enterprises, the UEN average of the state-owned enterprises is 0.98 , lower than the private enterprises, which is 0.994 . On the contrary, the UEM average of the state-owned enterprises (0.712) is higher than private enterprises $(0.704)$. However, the standard deviations of state-owned enterprises are bigger than private enterprises from both UEN and UEM.

State-owned enterprises under government management can enjoy monopolies of strategic industries and get public capital support more easily, such as subsidies, preferential loans, and lower rates of taxation. However, state-owned enterprises also face stricter control and intervention by the government, and the Chinese government has already given high priority to environmental sustainability, regulations, and policies that firstly target state-owned enterprises. Furthermore, the study of Quan and $\mathrm{Wu}[40]$ based on Chinese listed firms showed that only state-owned companies can achieve economic performance enhancement to be environmentally sustainable. Therefore, at the early stage of sustainable development for logistics companies, state-owned enterprises would face more severe pressures and driving force from the government on environmental issues. They will dedicate more resources towards satisfying the policy requirements and being environmentally sustainability. Considering this, the UEM of state-owned enterprises would be higher than private enterprises. This result is also consistent with the finding of Fryxell and Lo [41], which indicated that managers in Chinese state-owned enterprises appeared to embrace stronger environmental ethical values over the private sector.

In contrast, private enterprises have decision-making autonomy on enterprise operations, and are often viewed as more dynamic and market-orientated than state-owned enterprises. Private logistics enterprises in China now account for a significant proportion of freight transportation activity. When facing environmental protection pressures, private enterprises may still make decisions that rely on commercial consideration to achieve maximum economic benefit using minimum inputs. Therefore, the UEN of private enterprises may be higher than state-owned enterprises.

\subsubsection{Statistical Test}

To further test whether statistical differences existed between the means of the groups divided by enterprise size and enterprise ownership on the unified efficiency under natural and managerial disposability, the Welch's ANOVA test and Welch's t-test were conducted [42]. The Welch's ANOVA method is appropriate for a situation when data has unequal variance, and it has lowest type 1 error compared to nonparametric methods [43]. Additionally, according to the simulation of Moder [43], the ANOVA test is not sensitive to situations when the data has an abnormal distribution. Therefore, this study chose Welch's ANOVA test to compare the differences across enterprise types. Furthermore, the 
Welch's t-test, which also does not require the assumption of equal variance, was used for a robust test. The statistical results are displayed in Tables 3 and 4 .

Table 3 reports the test results of the comparison between large enterprises and SMEs. According to Welch's ANOVA test, the UEN scores on SMEs and large enterprises are significantly different at the $p<0.05$ level. The Welch's t-test also shows that the mean score of UEN in SMEs is significantly higher than the mean score of UEN in large enterprises $(t=-3.880, p=0.000)$. The two tests on UEN both indicate that the difference between SMEs and large enterprise is statistically significant. On the test of UEM in different enterprise sizes, Welch's ANOVA test $(p=0.208)$ and Welch's t-test $(p=0.058)$ both indicate that the difference between SMEs and large enterprises on UEM is not large enough to be statistically significant.

Table 3. Comparison between SMEs and large enterprises.

\begin{tabular}{cccc}
\hline Welch's ANOVA Test & & & \\
\hline & F-Value & $\boldsymbol{p}$-Value & Adj R-Squared \\
\hline UEN & 6.730 & $0.014^{*}$ & 0.156 \\
UEM & 1.650 & 0.208 & 0.021 \\
\hline Welch's t-test & & & \\
\hline & t-Value & $\boldsymbol{p}$-Value & Welch's Degrees of Freedom \\
\hline UEN & -3.880 & $0.000^{*}$ & 21.050 \\
UEM & -1.612 & 0.058 & 31.690 \\
\hline
\end{tabular}

Note: * indicates the significance level at $p<0.05$

Table 4. Comparison between state-owned and private enterprises.

\begin{tabular}{cccc}
\hline \multicolumn{4}{c}{ Welch's ANOVA Test } \\
\hline Statistics & F-Value & $p$-Value & Adj R-Squared \\
\hline UEN & 6.140 & $0.019^{*}$ & 0.142 \\
UEM & 0.180 & 0.678 & -0.027 \\
\hline \multicolumn{4}{c}{ Welch's t-Test } \\
Statistics & t-Value & $p$-Value & Welch's Degrees of \\
\hline UEN & 2.418 & $0.011^{*}$ & 25.500 \\
UEM & 0.412 & 0.341 & 28.300 \\
\hline
\end{tabular}

Note: * indicates the significance level at $p<0.05$

This statistical difference of UEN between large enterprises and SMEs further backs up the aforementioned discussion on the operational character of logistics enterprises of different sizes. At the early stage of sustainability development, logistics companies with a smaller market scale could be more agile in their operations to arrange production factors in order to achieve maximum desirable outputs without worsening the environment. Furthermore, all SMEs are also private enterprises, which face less government intervention on environmental protection, which could further motivate SMEs' business strategy toward operational priority; in other words, improve their efficiency under natural disposability.

Table 4 reports the test results of the comparison between state-owned and private enterprises. According to Welch's ANOVA test, the UEN scores on state-owned and private enterprises are significantly different at the $p<0.05$ level. Welch's t-test also shows that the mean score of UEN in private enterprises is significantly higher than the mean score of UEN in state-owned enterprises $(\mathrm{t}=2.418, p=0.011)$. The two tests on UEN both indicate that the difference between private and 
state-owned enterprises is statistically significant. On the test of UEM in different enterprise ownerships, Welch's ANOVA test $(p=0.678)$ and Welch's t-test $(p=0.341)$ both indicate the difference between private and state-owned enterprises on UEM is not large enough to be statistically significant.

Given the rapid growth rate of the private logistics market in China, it would take a lot of effort to transfer the market-orientated strategy to a sustainable-orientated strategy in private enterprises with less government regulations. Therefore, under natural disposability, it is not surprising that the difference between state-owned and private enterprises on UEN is statistically significant; in other words, the UEN of private logistics companies is significantly higher than state-owned enterprises.

It is worth noting that neither the enterprise size nor enterprise ownership shows statistical differences on UEM. That is to say, the differences of UEM are not big enough among those enterprise groups. Given the primary stage of logistics' sustainable construction, enterprises need more time to proactively change their business strategy to be in accordance with environmental sustainability. As the sustainable business environment becomes healthier in the logistics and freight transportation industry in China, the UEM would be enhanced significantly. Additionally, large and state-owned enterprises tend to maintain higher levels of research and development (R\&D) investment than private enterprise [44]. State-owned enterprises, which have preferential treatment from the government, would have a greater advantage to reach the efficiency frontier under managerial disposability [31].

\section{Conclusions}

This paper explored the environmental sustainability development in Chinese logistics enterprises by using environmental assessment DEA methods. Given that the environmental efficiency of logistics in China has not been measured at the enterprise level, this paper attempted to fill the gap in the existing literature to employ environmental assessment into logistics' environmental sustainability. The environmental assessment of logistics enterprises would help logistics managers and policy makers understand the integrated state of environmental performance based on a real production arrangement, which would be a significant contribution to environmental sustainability in the Chinese freight transportation sector.

Based on the inputs and outputs data from listed logistics companies from 2016 to 2018, this study firstly calculated the unified efficiency of each DMU under natural and managerial disposability, then gave multiple comparisons on UEN and UEM by enterprise groups classified by enterprise size and ownership. Due to the unbalanced development of economic performance and environmental sustainability in the Chinese logistics industry, the UEN is higher than UEM for every logistics enterprise in the empirical results. The better performance of efficiency under natural disposability in SMEs and private enterprises was proven to be statistically significant while the efficiency comparison under managerial disposability all had no statistical differences. The empirical results further proved that the development of environmental sustainability in the Chinese freight transportation sector is still at its primary stage. When encountering environmental regulation from the outside, logistics companies, especially private logistics enterprises, may still put commercial consideration at first priority to achieve maximum economic benefit using minimum inputs.

Furthermore, the environmental assessment DEA was proven to be an efficient tool to figure out whether a company is resisting change or has begun taking proactive actions towards environmental protection. For future researches, firstly, though restricted by the availability of environmental data, this study chose $\mathrm{CO}_{2}$ emissions as the undesirable output. With the improving quality of data disclosure in the transportation sector, future study could consider using multiple environmental data for further investigation. Secondly, as an important member of the supply chain, the activities of logistics are within the whole network of supply chain operation. Therefore, the environmental efficiency of logistics could be further explored under the green supply chain management framework, which can be evaluated by network DEA according to Mirhedayatian and Azadi [45]. Moreover, the comparative analysis of the environmental efficiency in different regions, such as Chinese enterprises 
and cross-country enterprises, should be investigated due to the unique environmental and economic background in China.

Despite an increasing awareness of the harmful effects of freight transportation on the environment, efficiency assessment under economic and environmental operational priorities could provide an integrated picture of logistics' environmental development under sustainable business circumstances. There is still a long way to go on transforming logistics firms' operational strategy from an economic priority to an environmentally sustainable priority, which is the backbone of improving environmental performance from the enterprise perspective in the long run. Additionally, this study also provides significant insights for a comparative evaluation on environmental sustainability development in enterprises from other industries or regions.

Author Contributions: Conceptualization, J.L.; Funding acquisition, X.L.; Investigation, C.Y.; Project administration, X.L.; Writing—original draft, J.L.

Funding: This research and the APC was funded by "Beijing University of Posts and Telecommunications-Lansun Joint Laboratory for Intelligent Logistics and Commercialization Research", grant number B2018011.

Conflicts of Interest: The authors declare no conflict of interest.

\section{Appendix A}

Tables A1-A3 present the unified efficiency of LSP, port, and ocean carrier enterprises separately. Each table presents the UEN and UEM scores of listed company from 2016 to 2018.

Table A1. Unified efficiency of LSP.

\begin{tabular}{ccccc}
\hline Year & Stock Symbol & Company Name & UEN & UEM \\
\hline 2017 & $8430 . \mathrm{HK}$ & C\&N Holdings & 1.000 & 0.753 \\
2018 & $8430 . \mathrm{HK}$ & C\&N Holdings & 1.000 & 0.753 \\
2017 & $6083 . \mathrm{HK}$ & World-Link Logistics (Asia) & 1.000 & 0.858 \\
2017 & $0636 . \mathrm{HK}$ & Kerry Logistics & 1.000 & 0.708 \\
2018 & $0636 . \mathrm{HK}$ & Kerry Logistics & 1.000 & 1.000 \\
2017 & $0152 . \mathrm{HK}$ & Shenzhen International & 1.000 & 1.000 \\
2017 & $8292 . \mathrm{HK}$ & Worldgate Global Logistics & 1.000 & 0.769 \\
2018 & $8292 . \mathrm{HK}$ & Worldgate Global Logistics & 1.000 & 0.769 \\
2018 & $8482 . \mathrm{HK}$ & WAN Leader International & 1.000 & 1.000 \\
2017 & $0500 . \mathrm{HK}$ & Frontier Services Group & 0.991 & 0.754 \\
2018 & $0500 . \mathrm{HK}$ & Frontier Services Group & 0.990 & 0.756 \\
2017 & $6123 . \mathrm{HK}$ & YTO Express & 1.000 & 1.000 \\
2016 & $1292 . \mathrm{HK}$ & Changan Minsheng Logistics & 0.964 & 0.801 \\
2017 & $1292 . \mathrm{HK}$ & Changan Minsheng Logistics & 0.961 & 0.531 \\
2018 & $1292 . \mathrm{HK}$ & Changan Minsheng Logistics & 0.957 & 0.571 \\
2016 & $0598 . \mathrm{HK}$ & Sinotrans & 1.000 & 0.814 \\
2017 & $0598 . H K$ & Sinotrans & 1.000 & 1.000 \\
2018 & $0598 . H K$ & Sinotrans & 1.000 & 1.000 \\
\hline & & Average & 0.992 & 0.824 \\
& Statistics & Max. & 1.000 & 1.000 \\
& & Min. & 0.957 & 0.531 \\
\hline
\end{tabular}


Table A2. Unified efficiency of port.

\begin{tabular}{ccccc}
\hline Year & Stock Symbol & Company Name & UEN & UEM \\
\hline 2017 & $2880 . H K$ & DaLian Port (PDA) & 0.930 & 0.495 \\
2018 & $2880 . H K$ & DaLian Port (PDA) & 0.928 & 0.480 \\
2017 & $3369 . H K$ & Qinhuangdao Port & 1.000 & 0.801 \\
2018 & $3369 . H K$ & Qinhuangdao Port & 0.937 & 0.795 \\
2016 & $6198 . H K$ & Qingdao Port International & 0.966 & 0.712 \\
2017 & $6198 . H K$ & Qingdao Port International & 0.985 & 0.772 \\
2018 & $6198 . H K$ & Qingdao Port International & 1.000 & 0.805 \\
2016 & $3378 . H K$ & XiaMen Port & 0.963 & 0.616 \\
2017 & $3378 . H K$ & XiaMen Port & 0.970 & 0.613 \\
2018 & $3378 . H K$ & XiaMen Port & 0.966 & 0.598 \\
2017 & $8157 . H K$ & XIANGXING International & 1.000 & 1.000 \\
2018 & $8157 . H K$ & XIANGXING International & 1.000 & 0.813 \\
2017 & $1990 . H K$ & Xinghua Port & 1.000 & 0.745 \\
2018 & $8502 . H K$ & Ocean Line Port Development & 1.000 & 0.754 \\
2016 & $0144 . H K$ & China Merchants Port & 1.000 & 0.936 \\
2017 & $0144 . H K$ & China Merchants Port & 0.978 & 1.000 \\
2018 & $0144 . H K$ & China Merchants Port & 1.000 & 1.000 \\
2016 & $1199 . H K$ & COSCO SHIPPING Ports & 0.957 & 0.478 \\
2017 & $1199 . H K$ & COSCO SHIPPING Ports & 1.000 & 0.627 \\
2018 & $1199 . H K$ & COSCO SHIPPING Ports & 1.000 & 0.535 \\
\hline
\end{tabular}

Table A3. Unified efficiency of ocean carrier.

\begin{tabular}{|c|c|c|c|c|}
\hline Year & Stock Symbol & Company Name & UEN & UEM \\
\hline 2017 & 8310.HK & $\begin{array}{c}\text { Dafeng Port Heshun } \\
\text { Technology }\end{array}$ & 1.000 & 0.387 \\
\hline 2018 & 8310.HK & $\begin{array}{c}\text { Dafeng Port Heshun } \\
\text { Technology }\end{array}$ & 1.000 & 0.384 \\
\hline 2017 & 0316.HK & Orient Overseas & 0.958 & 0.600 \\
\hline 2018 & 0316.HK & Orient Overseas & 1.000 & 0.607 \\
\hline 2016 & 1308.HK & SITC International & 0.982 & 0.432 \\
\hline 2017 & 1308.HK & SITC International & 1.000 & 0.450 \\
\hline 2018 & 1308.HK & SITC International & 1.000 & 0.454 \\
\hline 2017 & 0137.HK & JINHUI Holdings Company & 0.990 & 0.376 \\
\hline 2018 & 0137.HK & JINHUI Holdings Company & 1.000 & 0.379 \\
\hline 2018 & 2322.HK & Hong Kong ChaoShang Group & 1.000 & 0.855 \\
\hline 2018 & 3683.HK & Great Harvest Maeta Group & 1.000 & 0.574 \\
\hline 2017 & 2343.HK & Pacific Basin Shipping & 0.937 & 0.432 \\
\hline 2018 & 2343.HK & Pacific Basin Shipping & 0.949 & 0.451 \\
\hline 2017 & 0351.HK & Asia Energy Logistics & 1.000 & 0.748 \\
\hline 2018 & 0351.HK & Asia Energy Logistics & 1.000 & 0.706 \\
\hline 2016 & 1549.HK & Ever Harvest Group & 0.999 & 0.709 \\
\hline 2017 & 1549.HK & Ever Harvest Group & 0.999 & 0.714 \\
\hline 2018 & 1549.HK & Ever Harvest Group & 0.999 & 0.712 \\
\hline 2016 & 2866.HK & COSCO Shipping Development & 1.000 & 1.000 \\
\hline 2017 & 2866.HK & COSCO Shipping Development & 1.000 & 1.000 \\
\hline 2018 & 2866.HK & COSCO Shipping Development & 1.000 & 0.958 \\
\hline 2017 & 1919.HK & COSCO SHIPPING Holdings & 1.000 & 1.000 \\
\hline 2018 & 1919.HK & COSCO SHIPPING Holdings & 1.000 & 1.000 \\
\hline 2016 & 1138.HK & COSCO Shipping Energy & 1.000 & 0.508 \\
\hline 2017 & 1138.HK & COSCO Shipping Energy & 0.952 & 0.510 \\
\hline 2016 & 0560.HK & Chu Kong Shipping & 0.988 & 0.403 \\
\hline 2017 & 0560.HK & Chu Kong Shipping & 0.939 & 0.300 \\
\hline \multirow{3}{*}{\multicolumn{2}{|c|}{ Statistics }} & Average & 0.989 & 0.616 \\
\hline & & Max. & 1.000 & 1.000 \\
\hline & & Min. & 0.937 & 0.300 \\
\hline
\end{tabular}

Table A4 displays the categories of each company which classified by ownership and enterprise size. 
Table A4. Classification of each company.

\begin{tabular}{|c|c|c|c|}
\hline Stock Symbol & Company Name & Ownership & Size \\
\hline 0137.HK & JINHUI Holdings Company & Private & Large enterprise \\
\hline 0144.HK & China Merchants Port & State-owned & Large enterprise \\
\hline 0152.HK & Shenzhen International & State-owned & Large enterprise \\
\hline 0316.HK & Orient Overseas & State-owned & Large enterprise \\
\hline 0351.HK & Asia Energy Logistics & Private & SME \\
\hline 0500.HK & Frontier Services Group & Private & Large enterprise \\
\hline 0560.HK & Chu Kong Shipping & State-owned & Large enterprise \\
\hline 0598.HK & Sinotrans & State-owned & Large enterprise \\
\hline 0636.HK & Kerry Logistics & Private & Large enterprise \\
\hline 1138.HK & COSCO Shipping Energy & State-owned & Large enterprise \\
\hline 1199.HK & COSCO SHIPPING Ports & State-owned & Large enterprise \\
\hline 1292.HK & Changan Minsheng Logistics & State-owned & Large enterprise \\
\hline 1308.HK & SITC International & Private & Large enterprise \\
\hline 1549.HK & Ever Harvest Group & Private & SME \\
\hline 1919.HK & COSCO SHIPPING Holdings & State-owned & Large enterprise \\
\hline 1990.HK & Xinghua Port & Private & Large enterprise \\
\hline 2322.HK & Hong Kong ChaoShang Group & Private & SME \\
\hline 2343.HK & Pacific Basin Shipping & Private & Large enterprise \\
\hline 2866.HK & COSCO Shipping Development & State-owned & Large enterprise \\
\hline 2880.HK & DaLian Port (PDA) & State-owned & Large enterprise \\
\hline 3369.HK & Qinhuangdao Port & State-owned & Large enterprise \\
\hline 3378.HK & XiaMen Port & State-owned & Large enterprise \\
\hline 3683.HK & Great Harvest Maeta Group & Private & SME \\
\hline 6083.HK & World-Link Logistics (Asia) & Private & SME \\
\hline 6123.HK & YTO Express & Private & Large enterprise \\
\hline 6198.HK & Qingdao Port International & State-owned & Large enterprise \\
\hline 8157.HK & XIANGXING International & Private & SME \\
\hline 8292.HK & Worldgate Global Logistics & Private & SME \\
\hline 8310.HK & Dafeng Port & State-owned & Large enterprise \\
\hline 8430.HK & C\&N Holdings & Private & SME \\
\hline 8482.HK & WAN Leader International & Private & SME \\
\hline 8502.HK & Ocean Line Port Development & Private & SME \\
\hline
\end{tabular}

\section{References}

1. Liimatainen, H.; Hovi, I.B.; Arvidsson, N.; Nykänen, L. Driving forces of road freight CO2 in 2030. Int. J. Phys. Distrib. Logist. Manag. 2015, 45, 260-285. [CrossRef]

2. ITF. How Transport CO2 Reduction Pledges Fall Short; The International Transport Forum: Paris, France, 2018; p. 5 .

3. Marchet, G.; Melacini, M.; Perotti, S. Environmental sustainability in logistics and freight transportation: A literature review and research agenda. J. Manuf. Technol. Manag. 2014, 25, 775-811. [CrossRef]

4. Pazirandeh, A.; Jafari, H. Making sense of green logistics. Int. J. Product. Perform. Manag. 2013, 62, 889-904. [CrossRef]

5. Ellram, L.M.; Murfield, M.L.U. Environmental sustainability in freight transportation: A systematic literature review and agenda for future research. Transp. J. 2017, 56, 263-298. [CrossRef]

6. Zhou, P.; Wen, W. Carbon-constrained firm decisions: From business strategies to operations modeling. Eur. J. Oper. Res. 2019, 281, 1-15. [CrossRef]

7. NDRC. National Logistics Operation Report in 2018. Available online: http://www.ndrc.gov.cn/jjxsfx/201903/ t20190327_931373.html (accessed on 27 March 2019).

8. Duan, H.; Hu, M.; Zhang, Y.; Wang, J.; Jiang, W.; Huang, Q.; Li, J. Quantification of carbon emissions of the transport service sector in China by using streamlined life cycle assessment. J. Clean. Prod. 2015, 95, 109-116. [CrossRef]

9. Jeswani, H.K.; Wehrmeyer, W.; Mulugetta, Y. How warm is the corporate response to climate change? Evidence from Pakistan and the UK. Bus. Strategy Environ. 2008, 17, 46-60. [CrossRef]

10. Charnes, A.; Cooper, W.W.; Rhodes, E. Measuring the efficiency of decision making units. Eur. J. Oper. Res. 1978, 2, 429-444. [CrossRef]

11. Färe, R.; Grosskopf, S.; Lovell, C.K.; Pasurka, C. Multilateral productivity comparisons when some outputs are undesirable: A nonparametric approach. Rev. Econ. Stat. 1989, 71, 90-98. [CrossRef] 
12. Sueyoshi, T.; Yuan, Y.; Goto, M. A literature study for DEA applied to energy and environment. Energy Econ. 2017, 62, 104-124. [CrossRef]

13. Camarero, M.; Castillo, J.; Picazo-Tadeo, A.J.; Tamarit, C. Eco-efficiency and convergence in OECD countries. Environ. Resour. Econ. 2013, 55, 87-106. [CrossRef]

14. Camarero, M.; Castillo-Giménez, J.; Picazo-Tadeo, A.J.; Tamarit, C. Is eco-efficiency in greenhouse gas emissions converging among European Union countries? Empir. Econ. 2014, 47, 143-168. [CrossRef]

15. Cui, Q.; Li, Y. An empirical study on the influencing factors of transportation carbon efficiency: Evidences from fifteen countries. Appl. Energy 2015, 141, 209-217. [CrossRef]

16. Sueyoshi, T.; Yuan, Y. Measuring energy usage and sustainability development in Asian nations by DEA intermediate approach. J. Econ. Struct. 2018, 7, 6. [CrossRef]

17. Zhou, X.; Chen, H.; Wang, H.; Lev, B.; Quan, L. Natural and managerial disposability based DEA Model for China's regional environmental efficiency assessment. Energies 2019, 12, 3436. [CrossRef]

18. Sueyoshi, T.; Yuan, Y. Returns to damage under undesirable congestion and damages to return under desirable congestion measured by DEA environmental assessment with multiplier restriction: Economic and energy planning for social sustainability in China. Energy Econ. 2016, 56, 288-309. [CrossRef]

19. Sueyoshi, T.; Yuan, Y. China's regional sustainability and diversified resource allocation: DEA environmental assessment on economic development and air pollution. Energy Econ. 2015, 49, 239-256. [CrossRef]

20. Sueyoshi, T.; Wang, D. DEA environmental assessment on US petroleum industry: Non-radial approach with translation invariance in time horizon. Energy Econ. 2018, 72, 276-289. [CrossRef]

21. Sueyoshi, T.; Goto, M. Comparison among Three Groups of Solar Thermal Power Stations by Data Envelopment Analysis. Energies 2019, 12, 2454. [CrossRef]

22. Sueyoshi, T.; Goto, M. DEA environmental assessment in time horizon: Radial approach for Malmquist index measurement on petroleum companies. Energy Econ. 2015, 51, 329-345. [CrossRef]

23. Sueyoshi, T.; Goto, M. Environmental assessment by DEA radial measurement: US coal-fired power plants in ISO (Independent System Operator) and RTO (Regional Transmission Organization). Energy Econ. 2012, 34, 663-676. [CrossRef]

24. Sueyoshi, T.; Goto, M. DEA approach for unified efficiency measurement: Assessment of Japanese fossil fuel power generation. Energy Econ. 2011, 33, 292-303. [CrossRef]

25. Li, A.; Zhang, A.; Huang, H.; Yao, X. Measuring unified efficiency of fossil fuel power plants across provinces in China: An analysis based on non-radial directional distance functions. Energy 2018, 152, 549-561. [CrossRef]

26. Sueyoshi, T.; Goto, M. DEA Non-Radial Approach for Resource Allocation and Energy Usage to Enhance Corporate Sustainability in Japanese Manufacturing Industries. Energies 2019, 12, 1785. [CrossRef]

27. Sueyoshi, T.; Goto, M. Resource utilization for sustainability enhancement in Japanese industries. Appl. Energy 2018, 228, 2308-2320. [CrossRef]

28. Yang, C.; Taudes, A.; Dong, G. Efficiency analysis of European Freight Villages: Three peers for benchmarking. Cent. Eur. J. Oper. Res. 2017, 25, 91-122. [CrossRef]

29. Haralambides, H.; Gujar, G. On balancing supply chain efficiency and environmental impacts: An eco-DEA model applied to the dry port sector of India. Marit. Econ. Logist. 2012, 14, 122-137. [CrossRef]

30. Azadi, M.; Shabani, A.; Khodakarami, M.; Saen, R.F. Planning in feasible region by two-stage target-setting DEA methods: An application in green supply chain management of public transportation service providers. Transp. Res. Part E Logist. Transp. Rev. 2014, 70, 324-338. [CrossRef]

31. Li, Z.; Meng, N.; Yao, X. Sustainability performance for China's transportation industry under the environmental regulation. J. Clean. Prod. 2017, 142, 688-696. [CrossRef]

32. Sueyoshi, T.; Yuan, Y. Comparison among US industrial sectors by DEA environmental assessment: Equipped with analytical capability to handle zero or negative in production factors. Energy Econ. 2015, 52, 69-86. [CrossRef]

33. Sueyoshi, T.; Goto, M. Data envelopment analysis for environmental assessment: Comparison between public and private ownership in petroleum industry. Eur. J. Oper. Res. 2012, 216, 668-678. [CrossRef]

34. WBCSD. The Greenhouse Gas Protocol. In A Corporate Accounting and Reporting Standard; World Business Council for Sustainable Development: Washington, DC, USA, 2015. 
35. Sueyoshi, T.; Goto, M. Japanese fuel mix strategy after disaster of Fukushima Daiichi nuclear power plant: Lessons from international comparison among industrial nations measured by DEA environmental assessment in time horizon. Energy Econ. 2015, 52, 87-103. [CrossRef]

36. Wang, H.; Lu, X.; Deng, Y.; Sun, Y.; Nielsen, C.P.; Liu, Y.; Zhu, G.; Bu, M.; Bi, J.; McElroy, M.B. China's CO2 peak before 2030 implied from characteristics and growth of cities. Nat. Sustain. 2019, 2, 748-754. [CrossRef]

37. NBS. Division Standard of Large, Medium and Small Sized Industrial Enterprises; National Bureau of Statistics: Beijing, China, 2017.

38. Lin, C.-Y.; Ho, Y.-H. Determinants of Green Practice Adoption for Logistics Companies in China. J. Bus. Ethics 2011, 98, 67-83. [CrossRef]

39. Kudla, N.L.; Klaas-Wissing, T. Sustainability in shipper-logistics service provider relationships: A tentative taxonomy based on agency theory and stimulus-response analysis. J. Purch. Supply Manag. 2012, 18, 218-231. [CrossRef]

40. Quan, Y.; Wu, H.; Li, S.; Ying, S.X. Firm sustainable development and stakeholder engagement: The role of government support. Bus. Strategy Environ. 2018, 27, 1145-1158. [CrossRef]

41. Fryxell, G.E.; Lo, C.W.H. Organizational Membership and Environmental Ethics: A Comparison of Managers in State-owned Firms, Collectives, Private Firms and Joint Ventures in China. World Dev. 2001, 29, 1941-1956. [CrossRef]

42. Saeidi, S.; Jouybanpour, P.; Mirvakilli, A.; Iranshahi, D.; Klemeš, J.J. A comparative study between Modified Data Envelopment Analysis and Response Surface Methodology for optimisation of heterogeneous biodiesel production from waste cooking palm oil. J. Clean. Prod. 2016, 136, 23-30. [CrossRef]

43. Moder, K. Alternatives to F-test in one way ANOVA in case of heterogeneity of variances (a simulation study). Psychol. Test Assess. Model. 2010, 52, 343-353.

44. Dai, X.; Cheng, L. Public selection and research and development effort of manufacturing enterprises in China: State owned enterprises versus non-state owned enterprises. Innovation 2015, 17, 182-195. [CrossRef]

45. Mirhedayatian, S.M.; Azadi, M.; Saen, R.F. A novel network data envelopment analysis model for evaluating green supply chain management. Int. J. Prod. Econ. 2014, 147, 544-554. [CrossRef]

(C) 2019 by the authors. Licensee MDPI, Basel, Switzerland. This article is an open access article distributed under the terms and conditions of the Creative Commons Attribution (CC BY) license (http://creativecommons.org/licenses/by/4.0/). 